\title{
Menstrual characteristics and association of body mass index with dysmenorrhoea among the medical students in South India
}

\author{
Anju Arpana ${ }^{1}$, Lokeshwari ${ }^{2 *}$, Rashmi BM ${ }^{3}$ \\ ${ }^{1-3}$ Assistant Professor, ${ }^{1,2}$ Department of Obstetrics and Gynaecology, ${ }^{3}$ Dept. of Community Medicine, ${ }^{1}$ BGS Global Institute of Medical \\ Sciences, Bengaluru, Karnataka, ${ }^{2,3}$ Basaveshwara Medical College Hospital and Research Centre Chitradurga, Karnataka, India \\ *Corresponding Author: Lokeshwari K \\ Email: lokeshwari.kannayan@gmail.com
}

Received: $23^{\text {th }}$ March, 2019

Accepted: $10^{\text {th }}$ April, 2019

\begin{abstract}
Introduction: Menstrual cycle is a physiological phenomenon consisting of cyclical shedding of endometrium, occurring on an average of $28 \pm 7$ days in every woman's life in response to hormones during their reproductive years. The production of hormones from hypothalamus (gonadotropin-releasing hormone), pituitary (FSH and LH) and ovaries (progesterone and androstenedione, etc.) are regulated by positive and negative feedback mechanisms. The interaction of these hormones result in the menstrual cycles. Dysmenorrhea, is a cyclical painful cramping sensation in the lower abdomen, which might radiate to the back, occurring before and/or during menstruation. Its prevalence ranges between $25-90 \%$. Medical students endure relatively greater amount of stress due to the vast subject which is to be studied in their MBBS course coupled with the lack of outdoor physical activity. Also, a high prevalence of irregularity of periods if undetected early can lead to polycystic ovarian diseases which are one of the causes of infertility. The menstrual characteristics (the menstrual cycle bleeding patterns, length, etc.) are important indicators of endocrine and uterine dysfunctions/abnormalities like Polycystic Ovarian Disorders. Therefore, this study was conducted to assess the menstrual pattern in young adult females.

Material and Methods: A cross sectional study was conducted among female MBBS students and interns of a medical college in South India. Data was collected in a semi-structured questionnaire consisting of details regarding the menstrual history followed by clinical examination and relevant investigations as necessary.

Results: Total 204 female MBBS students with an average age of $21.1 \pm 2$ years participated in the study. Polymenorrhea and oligomenorrhea was seen in 3\% and $13 \%$ of the students respectively. Dysmenorrhea was reported by $53.9 \%$ of the students. Study found that a high percentage $(83.3 \%)$ of students who were over weight/obese suffered from dysmenorrhea. Whereas a lesser percentage underweight $(40.5 \%)$ and normal weight $(59.3 \%)$ students suffered from dysmenorrhea. This association was found to be statistically significant.

Conclusion: Early diagnosis and management of dysmenorrhea should be done and appropriate necessary life style modification should be encouraged among young females to reduce the incidence of PCOD and metabolic syndrome later in life.
\end{abstract}

Keywords: Dysmenorrhea, PCOD, Medical students, South India.

\section{Introduction}

Menstrual cycle is the physiological phenomenon, consisting of cyclical shedding of endometrium, occurring on an average of $28 \pm 7$ days in every woman's life in response to hormones during their reproductive years. An average blood loss of $50 \pm 30 \mathrm{ml}$ occurs in every menstrual cycle which lasts for about 5 days, accounting to around 67 months of menstrual bleeding over a lifetime of a female. ${ }^{1,2}$ The production of hormones from hypothalamus (gonadotropin-releasing hormone), pituitary (follicle stimulating hormone and luteinizing hormone) and ovaries (progesterone and androstenedione, etc.) are regulated by positive and negative feedback mechanisms. The interaction and the levels of these hormones regulate the duration and regularity of the menstrual cycles, ${ }^{1-5}$

The aetiology of menstrual disorders such as dysmenorrhea, premenstrual symptoms, menorrhagia, polymenorrhea, abnormal vaginal bleeding, amenorrhea, oligomenorrhea and irregular menstruation among the can be due to various psychological as well as organic causes. The increased levels of stress can affect the hormonal milieu, there by affecting the menstrual cycles. ${ }^{5}$ There are various types of menstrual disorders, including dysmenorrhea, premenstrual symptoms, menorrhagia, polymenorrhea, abnormal vaginal bleeding, amenorrhea, oligomenorrhea, and irregular menstruation. Studies have shown that a large proportion of the female population of reproductive age suffers from menstruation-related health issues. Menstrual problems not only carry an economic burden but are also one of the most common causes of absenteeism and poor academic performance among young females, affecting their social, physical and psychological dimensions of health. ${ }^{1,2,4,5}$

Dysmenorrhea, is a cyclical painful cramping sensation in the lower abdomen, which might radiate to the back, occurring before and/or during menstruation. Other symptoms associated with dysmenorrhea are fatigue, nausea, gastrointestinal disturbances, dizziness, fatigue among others. ${ }^{6-10}$ The causes of dysmenorrhea are higher levels of endometrial prostaglandins. It begins soon after menarche. It is the most common gynaecologic complaint among adolescent and adult females. ${ }^{8,11}$ The exact prevalence and epidemiology of primary dysmenorrhea is tough to be ascertained because it is a symptom that is perceived subjectively by females and also there has not been a standard diagnostic criteria applied to assess 
dysmenorrhea by researchers. There is a wide range in the documented global prevalence of dysmenorrhea (25 to 90\%) among women. Around $10 \%$ of Indian population comprise of people in the age group of 18-25 years, of which, about $50 \%$ is female population. ${ }^{5}$ In India, dysmenorrhea prevalence ranges between $50-87 \% .^{8,12-14}$

The medical students endure relatively greater amount of stress due to the vast subject which is to be studied during their MBBS course. The medical students also lack sufficient outdoor physical activity. ${ }^{5}$ A high prevalence of irregularity of periods among them if undetected in early stages, can lead to polycystic ovarian disease which is one of the causes of infertility. ${ }^{15}$ The menstrual characteristics (the menstrual cycle bleeding patterns, length, etc.) are important indicators of endocrine and uterine dysfunctions/abnormalities like Polycystic Ovarian Disorders. ${ }^{4}$ Therefore, this study was conducted to assess the menstrual pattern in young adult females

\section{Materials and Methods}

After obtaining institutional ethics committee approval, a cross sectional study was conducted among female MBBS students and interns of Basaveshwara Medical College \& Hospital, Chitradurga in the year of 2018 (September to November). Data was collected in a semi-structured questionnaire which was administered to all undergraduate female medical students in the age group of 18-25years, after explaining the purpose of the study and obtaining their informed consent.

The questionnaire consisted of details regarding the menstrual history- the duration and amount of flow of recent three menstrual cycles, associated symptoms like dysmenorrhoea, leg cramps, and any other bodily changes like weight gain, hair growth etc was taken. These students were later clinically examined by OBG specialist and their anthropometric measurements such as height, weight BMI, any signs of hirsutism or androgenism were recorded.

Exclusion criteria consisted of students who were married, those students who were on hormonal medication and primary amenorrhoeic females. A total of 204 female students participated in this study.

\section{Statistical Analysis}

The data was compiled in Microsoft excel spread sheet and analyzed using SPSS for windows version 16.0. All the characteristics are summarized descriptively. For continuous variables, the summary statistics of $\mathrm{N}$ and mean were used. For categorical data, the number and percentage were used in the data summarized. Chi square test was applied to test the significance of association of categorical variables.

\section{Results}

A total of 204 female students who met the inclusion criteria participated in the study.

The average age of the students was $21.1 \pm 2$ years. A $3 \%$ of the students had polymenorrhoea i.e. menstrual interval of less than 21 days. Oligomenorrhoea i.e. menstrual interval of more than 35 days was found in $13 \%$ of participants. Length of the menstrual interval was normal (i.e. 21-35 days) in $77 \%$ of the students whereas $7 \%$ students had irregular menstrual cycle.

Bleeding period varied from 1 to 12 days in last three menstrual cycles in the study population. A $10.8 \%$ students had duration of bleeding of less than 3 days while maximum $75 \%$ had normal duration of bleeding of 3-6 days. A $13.2 \%$ had duration of bleeding of more than 6 days while $2(1.0 \%)$ students reported to have bleeding for more than 10 days in last three cycles.

In the present study, a majority $(57.8 \%)$ of the students were in the normal weight range. A $5.9 \%$ of the students were overweight/obese (Table 2). Chi square test was applied to test the association of dysmenorrhea with body mass index among the participants. It was found that high percentage $(83.3 \%)$ of students who were overweight/obese were reportedly suffering from dysmenorrhea. Whereas a lesser percentage underweight $(40.5 \%)$ and normal weight $(59.3 \%)$ students were reportedly suffering from dysmenorrhea. This association was found to be statistically significant. (Table 3)

Table 1: Menstrual cycle characteristics among the participants

\begin{tabular}{|c|c|c|}
\hline Menstrual cycle characteristics & No of students (n) & Percentage (\%) \\
\hline Menstrual interval & & 3 \\
\hline$<21$ days & 6 & 77 \\
\hline $21-35$ days & 157 & 13 \\
\hline$>35$ days & 27 & 7 \\
\hline Irregular & 14 & 100 \\
\hline Total & 204 & 10.8 \\
\hline Duration of bleeding & & 75.0 \\
\hline$<3$ & 22 & 13.2 \\
\hline $3-6$ & 153 & 1.0 \\
\hline$>6$ & 27 & 100 \\
\hline$>10$ & 2 & \\
\hline Total & 204 & \\
\hline & & \\
\hline
\end{tabular}


Table 2: The distribution of the participant students according to their BMI

\begin{tabular}{|c|c|c|}
\hline BMI $\left(\mathbf{K g} / \mathbf{m t}^{\mathbf{2}}\right)$ & Number of students $\mathbf{~} \mathbf{N = 2 0 4})$ & Percentage (\%) \\
\hline$<18.5$ & 74 & 36.3 \\
\hline $18.5-24.99$ & 118 & 57.8 \\
\hline$\geq 25$ & 12 & 5.9 \\
\hline Total & 204 & 100 \\
\hline
\end{tabular}

Table 3: Association of BMI with dysmenorrhea

\begin{tabular}{|c|c|c|c|}
\hline $\begin{array}{c}\mathbf{B M I} \\
\left(\mathbf{K g} / \mathbf{m t}^{\mathbf{2}}\right)\end{array}$ & $\begin{array}{c}\text { Dysmenorrhea present } \\
\mathbf{n}(\boldsymbol{\%})\end{array}$ & $\begin{array}{c}\text { Dysmenorrhea absent } \\
\mathbf{n}(\boldsymbol{\%})\end{array}$ & $\begin{array}{c}\text { Total } \\
\mathbf{n}(\boldsymbol{\%})\end{array}$ \\
\hline$<18.5$ & $30(40.5 \%)$ & $44(59.5 \%)$ & $74(100.0 \%)$ \\
\hline $18.5-24.99$ & $70(59.3 \%)$ & $48(40.7 \%)$ & $118(100.0 \%)$ \\
\hline$\geq 25$ & $10(83.3 \%)$ & $2(16.7 \%)$ & $12(100.0 \%)$ \\
\hline Total & $110(53.9 \%)$ & $90(40.2 \%)$ & $204(94.1 \%)$ \\
\hline
\end{tabular}

Chi sq value: 10.8958 p: 0.0043

\section{Discussion}

Menstruation is the cyclic, orderly sloughing of the uterine lining, in response to the interactions of hormones produced by the hypothalamus, pituitary, and ovaries.

Menstruation is normal physiological process wherein cyclical and regular shedding of uterine endometrium occurs regulated by the positive and negative feedback mechanism of hormones secreted by hypothalamus, pituitary and ovaries. ${ }^{3,17}$ The regularity, duration and amount of menstrual bleeding are essential indicators of sexual development in females and they also help to rule out pathological conditions such as PCOD and other edocrinological disorders among young females. ${ }^{16}$ Menstrual abnormality has become a common complaint among young females starting right from late adolescence amongst nearly $75 \%$ of them. ${ }^{17}$

Menstrual disorders are menstrual irregularities either in duration or length such as hyper- or-hypomenorrhea, poly or oligomenorrhea, amenorrhea, menorrhagia, dysmenorrhea and PMS. ${ }^{18}$ In the present study, irregular cycles were seen in 7\% students (Table 1) which is lower than in study done by Dambhare DG et al among adolescent girls. ${ }^{19}$ This could be because our study was done in the age group of 18-25 years. By that time, body gets adjusted to the hormonal changes of puberty. ${ }^{20}$ Less prevalence of overweight/obesity (5.9\%) might be the reason for low incidence of menstrual irregularities and PCOD in our study group (Table 2)

In the present study, it was found that the length of the menstrual interval was normal i.e. 21-35 days in $77 \%$ of the students (Table 1) which is comparable to study done by Gayatri $\mathrm{G}$ et al. ${ }^{4}$ The mean duration of menstrual flow in our study was 4 days which is similar to the studies conducted by Dambhare DG et al and Nusrat $\mathrm{N}$ et al. ${ }^{19,21}$

In the present study, the age at attainment of menarche was reported to be at less than 16 years of age among all participants and hence none of them had primary amenorrhoea. None were morbidly obese. And 3 out of 204(1.5\%) students had been diagnosed with PCOD according to ultrasonic evidence of PCOD in our study. The results are comparable with the study conducted by Nidhi $R$ et al, whereas the study conducted by Kural $\mathrm{M}$ et al documented a higher prevalence of PCOD (22\%) which, according to the author was due to the use of different diagnostic criteria, study settings and age group of the sample studied. ${ }^{6,22}$ Less prevalence of obesity found in our study group, might be one the reasons for lower incidence of menstrual irregularities and PCOD. ${ }^{23}$

In the present study, dysmenorrhoea was seen in a total of $53.9 \%$ of students. The study also showed a significant association of dysmenorrhea with overweight/obesity (Table 2 and 3). Similar results are found in the study conducted by Chakrabarti $\mathrm{M}$ et al. ${ }^{24}$ Obesity is seen to be having close association with menstrual disturbances, dysmenorrhoea and PCOD. And it is seen that even average diet modification and physical exercise is associated with marked improvement in metabolic and endocrine functions. ${ }^{25}$ Rising trends in the prevalence of PCOS has become a great cause for health concern as it is increasing the incidence of metabolic syndrome. ${ }^{26}$

\section{Conclusion}

Lack of exercise and sedentary lifestyle in young adults are increasing the incidence of menstrual abnormalities and PCOD, which ultimately increases the risk of metabolic syndrome. Early diagnosis and management of dysmenorrhea should be done and appropriate necessary life style modification should be encouraged among young females to reduce the incidence of PCOD and metabolic syndrome later in life.

\section{Conflict of Interest: None.}

\section{References}

1. Beek, Jonathan S. Puberty and dysmenorrhea treatment. In: Novak's Gynecology. 14th Ed. London: Williams and Wilkins publication Inc; 2006. p. 1696.

2. Omidvar S, Begum K. Menstrual pattern among unmarried women from south India. J Nat Sci Biol Med [Internet]. 2011;2(2):174-9. Available from:

http://www.jnsbm.org/text.asp?2011/2/2/174/92329

3. Reed BG, Carr BR. The Normal Menstrual Cycle and the Control of Ovulation [Internet]. Feingold KR, Anawalt B, 
Boyce A, editors. Endotext [Internet]. 2018 [cited 2019 Mar 1]. Available from:

https://www.ncbi.nlm.nih.gov/books/NBK279054/

4. Godbole G, Phadake A, Joshi AR. Pattern of menstrual cycle in young adults. Indian J Basic Appl Med Res 2013;2(8):101721.

5. Sood M, Devi A, Daher A, Razali S, Nawawi H, Hashim S, et al. Poor Correlation of Stress Levels and Menstrual Patterns among Medical Students. J ASIAN Behav Stud 2017;2(5):73-8. Available from: http://dx.doi.org/10.21834/jabs.v2i5.221

6. Kural M, Noor NN, Pandit D, Joshi T, Patil A. Menstrual characteristics and prevalence of dysmenorrhea in college going girls. J Fam Med Prim Care 2015;4(3):426-31.

7. Raine-Fenning N. Dysmenorrhoea. Current Obstetrics \& Gynaecology. Curr Obstet Gynaecol. 2005;15(6):394-401.

8. Omidvar S, Bakouei F, Amiri FN, Begum K. Primary Dysmenorrhea and Menstrual Symptoms in Indian Female Students: Prevalence, Impact and Management. Glob J Health Sci 2016;8(8):135-42. Available from: http://www.ccsenet.org/journal/index.php/gjhs/article/view/536 32

9. ACOG. Premenstrual syndrome (PMS) [Internet]. ACOG. 2015 [cited $2019 \mathrm{Feb} 1]$. Available from: https://www.acog.org/Patients/FAQs/Premenstrual-SyndromePMS?IsMobileSet=false\#what

10. Gebeyehu M, Mekuria A, Tefera Y, Andarge D, Debay Y, Bejiga $\mathrm{G}$ et al. Prevalence, Impact, and Management Practice of Dysmenorrhea among University of Gondar Students, Northwestern Ethiopia: A Cross-Sectional Study. Int J Reprod Med 2017;1-8.

11. Doty E, Attaran M. Managing primary dysmenorrhea. $J$ Pediatr Adolesc Gynecol 2006;19(5):341-4.

12. Okusanya B. Menstrual pain and associated factors amongst undergraduates of Ambrose Alli University Ekpoma, Edo State, Niger 2014;2009.

13. Nair P, Grovel V, Kannan A. Awareness and Practices of Menstruation and Pubertal Changes Amongst Unmarried Female Adolescents in a Rural Area of East Delhi. IJCM 2007;32(2):156-7.

14. Singh A, Kiran D, Singh H, Nel B, Singh P, Tiwari P et al. Prevalence and severity of dysmenorrhea: a problem related to menstruation, among first and second year female medical students. Indian J Physiol Pharmacol 2008;52(4):389-97.
15. Beevi N, Manju L, Bindhu A, Haran JC, Jose R. Menstrual problems among adolescent girls in Thiruvananthapuram district. Int J Community Med Public Heal 2017;4(8):2995-8.

16. Dars S, Sayed K, Yousufzai Z. Relationship of menstrual irregularities to BMI and nutritional status in adolescent girls. Pak J Med Sci 2014;30(1):140-4.

17. Lee L, Chen P, Lee K, Kaur J. Menstruation adolescent Malaysia Lee Chen. Singapore Med J 2006;47(10):869-74.

18. Howard W. Novak's text book of gynecology. 12th ed. Williams and Wilkins, editor. Philadelphia; 1996.

19. Dambhare D, Wagh S, Dudhe J. No Title. Glob J Health Sci 2012;4(1):105.

20. Agarwal A, Venkat A. No Title. J Ped Adolesc Gyn 2009;22(6):365-71.

21. Nisar N, Zehra N, Haider G, Munir A, Sohoo NA. Frequency, Intensity and Impact of Premenstrual Syndrome in Medical Students. J Coll Physicians Surg Pakistan 2008;18(8):481-4.

22. Nidhi R, Padmalatha V, Nagarathna R, Amritanshu R. Prevalence of polycystic ovarian syndrome in Indian adolescents. J Pediatr Adolesc Gynecol 2011;24(4):223-7.

23. Gill $\mathrm{H}$, Tiwari P, Dabadghao P. Prevalence of polycystic ovary syndrome in young women from North India: A Communitybased study. Indian J Endocrinol Metab 2012;16(2):389-92.

24. Chakrabarti M, Rahaman A, Basu SP. Ultrasonographic Prevalence of Polycystic Ovarian Disease - A Cross-Sectional Study in a Rural Medical College of West Bengal. IOSR J Dent Med Sci 2016;15(1):115-20.

25. Yildiz BO, Knochenhauer ES, Azziz R. Impact of Obesity on the Risk for Polycystic Ovary Syndrome. J Clin Endocrinol Metab 2008;93(1):162-8.

26. Choudhary A, Jain S, Chaudhari P. Prevalence and symptomatology of polycystic ovarian syndrome in Indian women : is there a rising incidence? Int J Reprod Contracept Obs Gynecol 2017;6(11):4971-5.

How to cite this article: Arpana A, Lokeshwari K, Rashmi $\mathrm{BM}$, Menstrual characteristics and association of body mass index with dysmenorrhoea among the medical students in South India. Indian $J$ Obstet Gynecol Res 2019;6(2):155-158. 